\title{
Compound heterozygous POMGNT1 mutations leading to muscular dystrophy- dystroglycanopathy type A3: a case report
}

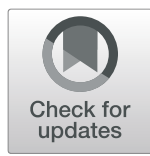

\author{
Kondakova Olga Borisovna', Krasnenko Anna Yurievna ${ }^{2,3}$, Tsukanov Kirill Yurievich², Klimchuk Olesya Igorevna², \\ Korostin Dmitriy Olegovich²,3, Davidova Anna Igorevna ${ }^{4}$, Batysheva Tatyana Timofeevna?', \\ Zhurkova Natalia Vyacheslavovna ${ }^{5}$, Surkova Ekaterina Ivanovna ${ }^{2 *}$ (D), Shatalov Peter Alekseevich ${ }^{2,6}$ and \\ Ilinsky Valery Vladimirovich, ${ }^{7,2,8}$
}

\begin{abstract}
Background: Dystroglycanopathies, which are caused by reduced glycosylation of alpha-dystroglycan, are a heterogeneous group of neurodegenerative disorders characterized by variable brain and skeletal muscle involvement. Muscle-eye-brain disease (or muscular dystrophy-dystroglycanopathy type $3 \mathrm{~A}$ ) is an autosomal recessive disorder characterized by congenital muscular dystrophy, ocular abnormalities, and lissencephaly.

Case presentation: We report clinical and genetic characteristics of a 6-year-old boy affected by muscular dystrophy-dystroglycanopathy. He has severe a delay in psychomotor and speech development, muscle hypotony, congenital myopia, partial atrophy of the optic nerve disc, increased level of creatine kinase, primary-muscle lesion, polymicrogyria, ventriculomegaly, hypoplasia of the corpus callosum, cysts of the cerebellum. Exome sequencing revealed compound heterozygous mutations in POMGNT1 gene (transcript NM_001243766.1): c.1539 + 1G > A and c. $385 C>T$.
\end{abstract}

Conclusions: The present case report shows diagnostic algorithm step by step and helps better understand the clinical and genetic features of congenital muscular dystrophy.

Keywords: Dystrophy-dystroglycanopathy, POMGNT1, MEB disease

\section{Background}

Congenital muscular dystrophy (CMD) is a clinically and genetically heterogeneous group of inherited muscle disorders characterized by hypotonia, delayed motor development and progressive muscle weakness. Muscle biopsies in patients with CMDs show considerable variability but always exhibit a characteristic pattern of dystrophic lesions. Disease typically manifests at birth or during the first year of life. The incidence of CMD in populations is not sufficiently known, there are small number of studies reporting incidence of $\mathrm{CMD}$ in several countries and regions: western Sweden $\left(6.3 \times 10^{5}\right)$, Northern England $\left(0.76 \times 10^{5}\right)$, north of Italy $\left(4.7 \times 10^{5}\right)[1-3]$.

\footnotetext{
* Correspondence: esurkova@genotek.ru

${ }^{2}$ Genotek Ltd, Nastavnicheskii pereulok 17/1, 105120 Moscow, Russia Full list of author information is available at the end of the article
}

Progress in the field of molecular genetics allowed to determine genes whose mutated forms are responsible for CMDs. Identification of genetic cause and accurate diagnosis improve supportive therapy and family planning. But currently there is no specific treatment for this group of diseases. The most common CMDs are Ulrich congenital muscular dystrophy (UCMD, OMIM 254090) due to the pathology of collagen VI (mutations are found in three genes) [4], secondary dystroglycanopathies associated with a violation of $\alpha$-dystroglycan (16 candidate genes) [5] and CMD caused by a primary merosin deficiency (merosin-deficient congenital muscular dystrophy, MDC1A) due to mutation of the LAMA2 gene [6].

Dystroglycanopathies are inherited in an autosomal recessive manner and characterized by brain and eye anomalies [7]. Clinical presentations can vary widely, 
from Walker-Warburg syndrome, a lethal perinatal form of congenital muscular dystrophy, to milder limb-girdle muscular dystrophy with manifestation in adulthood. To date, sixteen different genes are known as a cause of dystroglycanopathies: POMT1, POMT2, POMGNT1, FKTN, FKRP, LARGE, DPM2, DPM3, DOLK, ISPD, GTDC2, TMEM5, B3GALNT2, B3GNT1, GMPPB, DPM1 [8]. There is only one population study in which Graziano with colleagues identified prevalence of dystroglycanopathies in Italy as 0.226 per 100,000 [9]. But this prevalence may vary in different populations, often due to founder mutations.

Dystroglycan is composed of two subunits ( $\alpha$ and $\beta$ ) and is an essential component of the dystrophin-glycoprotein complex: linkage between the extracellular matrix and the membrane cytoskeleton in muscle fibers [10]. Destruction of the dystrophin-glycoprotein complex due to abnormalities in the structure of proteins or the violation of glycosylation leads to the development of muscular dystrophy. $\alpha$-dystroglycan is also involved in neuronal migration, and its violation leads to anomalies in CNS [11].

Clinical findings of dystroglycanopathy include hypotonia starting in early infancy, marked mental and motor retardation, seizures, eye abnormalities (myopia, glaucoma, cataract, optic nerve atrophy, retinal dysplasia, microphthalmia). The following CNS abnormalities are observed: pachygyria, polymicrogyria, lissencephaly, hydrocephalus, ventriculomegaly, agenesis of the corpus callosum, hypoplasia of the brain stem, hypoplasia, dysplasia or cysts of cerebellum [7]. The most frequent dystroglycanopathies include muscle eye brain disease (MEB) [7], Walker-Warburg syndrome (WWS) [12] and Fukuyama congenital muscular dystrophy (FCMD) [13].

CMD diagnosis can be challenging, and in some cases patients with muscular dystrophy received therapy to treat perinatal CNS damage or other neurological diseases. Genetic testing allows to confirm CMD diagnosis and identify the disease at an early stage [14]. In this study, we analyzed clinical and genetic characteristics of a 6-year-old boy with muscular dystrophy-dystroglycanopathy. The symptoms his parents reported were fatigue during sports activities, stereotypes, lack of speech acquisition, gradual cognitive decline and unsteadiness.

\section{Case presentation}

A 6-year-old boy was born of the second pregnancy and first childbirth to healthy nonconsanguineous parents. The first pregnancy ended in an early miscarriage. Family history is not burdened.

Pregnancy was with threatened spontaneous interruption. He was delivered by scheduled Cesarean section due to high myopia. His birth weight was $3650 \mathrm{~g}$ and height was $52 \mathrm{~cm}$. Apgar scores were 8 and 9 at 1 and 5 min respectively. He was noted to have hypotonia at birth.

His motor milestones were delayed: held head by 7 months, rolled from back to side at 8 months, put into sitting position by 24 months, walked with support at 2,5 years and walked independently at 4 years. His speech development was delayed: at the age of 6 years he had no words.

At 8 month he was hospitalized to Scientific and Practical Centre of Pediatric psychoneurology. Brain computed tomography revealed signs of leukodystrophy and cortical atrophy of frontal, parietal and temporal areas. Radiological studies (neuroimaging) have never been performed until the age of 8 months.

At 13 months he was admitted to the National Medical Research Centre for Children's Health and was monitored for the next 5 years.

At admission in 13 months brain MRI revealed signs of leukodystrophy, lissencephaly of left occipital lobe, polymicrogyria of both frontal lobes, secondary ventriculomegaly, brain atrophic changes with enlargement of sub-arachnoid spaces. Biochemical analysis showed creatine kinase (CK) level to be elevated to $2024 \mathrm{U} / \mathrm{L}$ (normal range 25-140 U/L), alanine aminotransferase (ALT) to $59 \mathrm{U} / \mathrm{L}$ (upper limit of normal $40 \mathrm{U} / \mathrm{L}$ ), aspartate aminotransferase (AST) to $82 \mathrm{U} / \mathrm{L}$ (upper limit of normal $42 \mathrm{U} / \mathrm{L}$ ) and lactate dehydrogenase (LDH) level to $318 \mathrm{U} / \mathrm{L}$ (upper limit of normal $225 \mathrm{U} / \mathrm{L}$ ). On electromyographic examination, signs of primary muscle lesion have been identified.

At admission in 6 years weight was $21 \mathrm{~kg}$, height was $113 \mathrm{~cm}$, head circumference was $53 \mathrm{~cm}$. Convergent strabismus, insufficiency of convergence and accommodation were noted. He had hypotonia, distal more than proximal. Trunk ataxia, walking on his toes with an atactic component, flat valgus foot were noted. Patient reacted favorably to examination. He can maintain short-term eye contact; speech is misunderstood. The face is hypomimic. In active speech there are long vocalized sounds, rarely - simple babbling syllables, no words. Behavioral features are manifested by periodic fading with subsequent rapidity of breathing and stereotyped swings of hands (Fig. 1).

Orthopedic examination revealed thoracic hypokyphosis, lumbar hyperlordosis, double-sided coxa valga, pathological antetorsion on the right, equinox flat valgus feet. Limb movements were not restricted except for restriction of back flexion in the ankles.

Ophthalmological examination revealed congenital high myopia, partial atrophy of an optic nerve and retinal atrophy in both eyes.

MRI revealed hypoplasia of temporal lobes and opercular areas from two sides, hypoplasia of caudal parts of the cerebellum worm with the expansion of external 


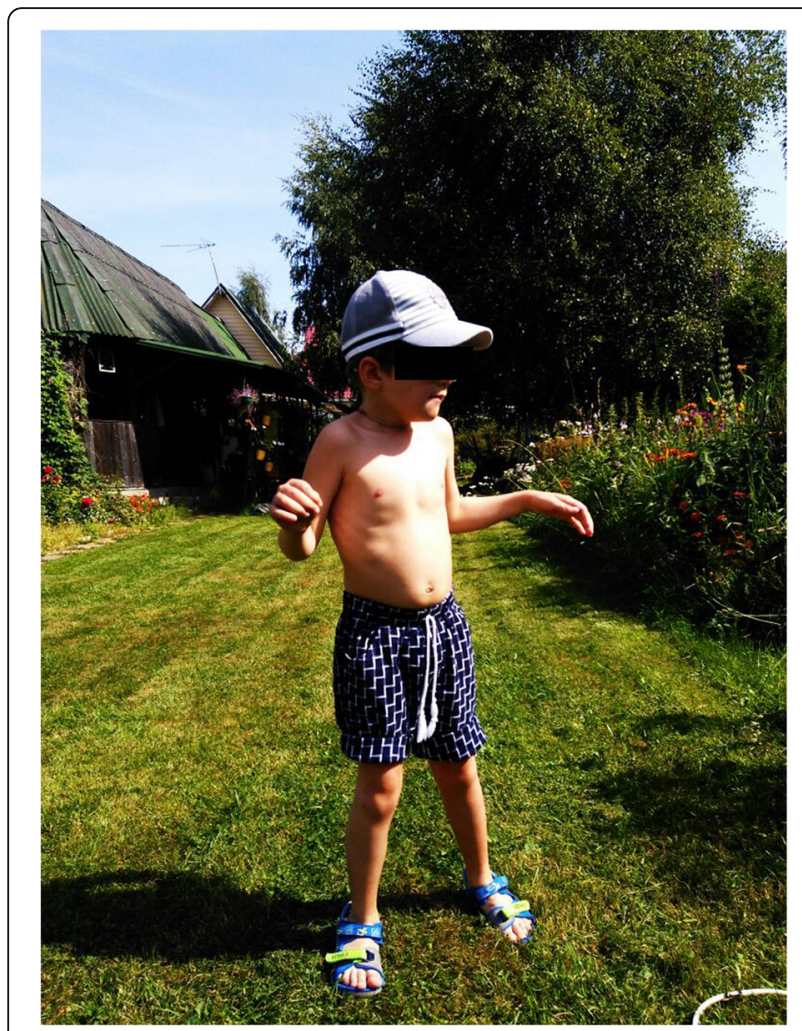

Fig. 1 Photograph of the patient showing phenotype and stereotypic movements

subarachnoid spaces of the cerebral hemispheres (more in the temporal areas), expansion of retrocerebellar cistern, symmetrical expansion of the ventricular system, pachygyria-polymicrogyria of cerebral hemispheres with preservation of the occipital lobe. Increased intensity of MR signal was observed in T2 and T2 FLAIR images. Decreased intensity of MR signal was observed in T1 image. In the cerebellum multiple small cysts, hypoplasia of the corpus callosum and pons with the extension of the anterior and covering cisterns are revealed (Fig. 2).

Biochemical analysis showed CK level to be elevated to $2253 \mathrm{U} / \mathrm{L}$ (normal range 25-194 U/L), ALT to 70,4 $\mathrm{U} / \mathrm{L}$ (upper limit of normal $40 \mathrm{U} / \mathrm{L}$ ), AST to $62 \mathrm{U} / \mathrm{L}$ (upper limit of normal $42 \mathrm{U} / \mathrm{L}$ ) and $\mathrm{LDH}$ level to 503 $\mathrm{U} / \mathrm{L}$ (upper limit of normal 314 U/L). Other blood and urine indicators were within normal limits. Patient level of CK was increased 10-15 times and for two years decreased from 3126 (3 years 4 months) to 1986 (at 5 years 2 months). The level of CK-MB was also increased - 61.1 (upper limit of normal $25 \mathrm{U} / \mathrm{L}$ ).

On electroneuromyographic examination (ENMG), signs of primary muscle lesion have been identified. Motor unit potentials (MUP) were short in duration and low in amplitude. The number of polyphasic MUP has increased. Spontaneous activity in each test muscle was determined.
Electroencephalography (EEG) did not reveal epileptiform activity.

The electrocardiogram (ECG) showed a vertical position of the electrical heart axis, mild bradycardia and arrhythmia, nonspecific intraventricular block, early repolarization syndrome of the ventricles.

A standard karyotype was normal 46, XY. Tandem mass spectrometry did not reveal any changes in the plasma level of amino acids and acylcarnitines.

Genotek Ltd. did clinical exome sequencing. Genomic DNA from peripheral blood sample was extracted using QIAamp DNA Mini Kit (Qiagen) according to manufacturer's protocol. DNA libraries were prepared using NEBNext Ultra DNA Library Prep Kit for Illumina (New England Biolabs) with adapters for sequencing on Illumina platform according to manufacturer's protocol. We used SureSelect XT2 (Agilent Technologies) for target enrichment. Enriched samples were sequenced on Illumina HiSeq 2500 using pair-end 100 base pairs reads. After sequencing, we trimmed 3'-nucleotides with read quality below 10 using Cutadapt [15]. Raw reads were aligned to reference genome hg19 (GRCh37.p13) using BWA MEM [16]. Deduplication of reads was done using SAMtools rmdup [17]. FastQS was used for data quality control [18]. We called short variants using GATK HaplotypeCaller [19] according to GATK Best Practices DNA-seq [20, 21]. The effect of each mutation was assessed using snpEff [22]. To assess pathogenicity and conservatism, the data was extracted from the dbNSFP [23], Clinvar [24, 25], OMIM database [26] and HGMD [27], as well as using the SIFT [28] and PolyPhen-2 [29, 30] utilities to predict pathogenicity of the mutation. Information on frequency of mutations was taken from 1000Genomes project [31, 32], ExAC [33, 34] and Genotek frequency data. Pathogenicity was predicted according to the Standards and Guidelines developed by ACMG (American College of Medical Genetics and Genomics), AMP (Association for Molecular Pathology) and CAP (College of American Pathologists) [35]. Copy number alterations were determined using CNVkit [36].

Sanger sequencing confirmed POMGNT1 pathogenic variants identified by exome sequencing. For labeling amplicons with fluorescent labels, BigDye Terminator Cycle Sequencing Kit v3.1 (Thermo Fisher Scientific) was used. Sanger sequencing was performed on ABI PRISM 3500 Genetic Analyzer (Applied Biosystems) according to manufacturer's protocol.

After exome sequencing, patient was commenced on muscle relaxants and anticonvulsants. His condition is stable.

\section{Discussion and conclusions}

In our patients, two heterozygous mutations c.1539+ $1 \mathrm{G}>\mathrm{A}$ and $\mathrm{c} .385 \mathrm{C}>\mathrm{T}$ of the POMGNT1 gene were 

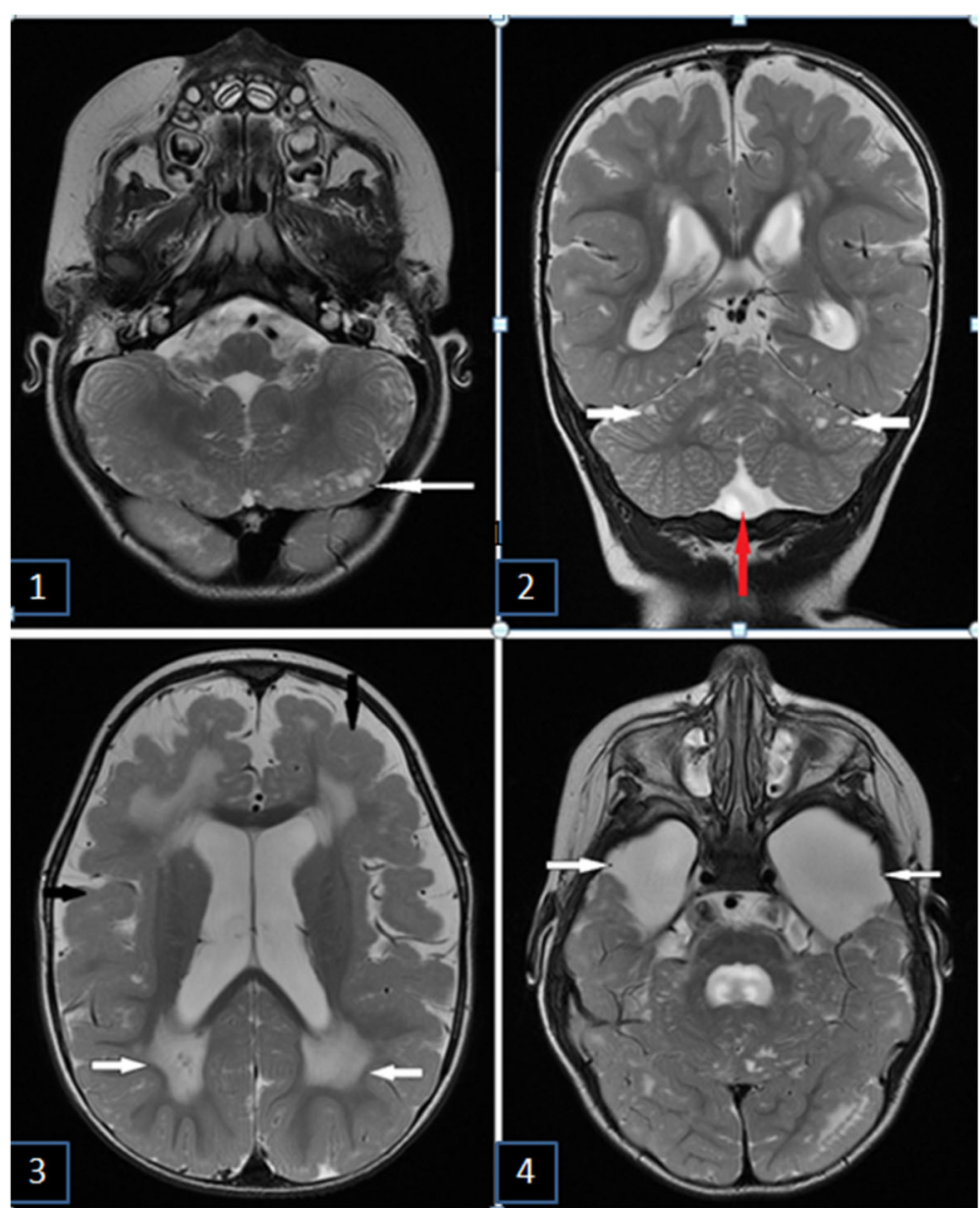

Fig. 2 Brain MRI of the 6-year-old boy with dystrophy-dystroglycanopathy. 1 - Multiple subcortical cerebellar cysts (white arrow). Axial T2 weighted image. $\mathbf{2}$ - Hypoplasia of caudal parts of the cerebellum worm (red arrow) and subcortical cerebellar cysts (white arrows). Frontal T2 weighted image. 3 - Pachygyria-polymicrogyria of frontotemporal lobes (type "cobblestone pavement") (black arrows) and demyelination of white matter (white arrows). Axial T2 weighted image. 4 - Hypoplasia of the temporal lobes (white arrows). Axial T2 weighted image

found by NGS analysis and confirmed by Sanger sequencing. First mutation c. $1539+1 \mathrm{G}>\mathrm{A}$ present in the father and second mutation c.385C $>\mathrm{T}$ present in the mother (Fig. 3). Thus, compound-heterozygous localization of these two mutations was confirmed. Mutations are described in the literature: c. $1539+1 \mathrm{G}>\mathrm{A}$ is a splice site pathogenic mutation in 17 intron [37-39], c.385C $>\mathrm{T}$ is likely pathogenic mutation in 5 exone.

Mutation c. $1539+1 G>$ A (chr1:46657769, genome build GRCh37) is a substitution in intron 17, which altered the conserved GT splicing donor sequence to AT. This mutation caused read-through of intronic sequences, resulting in the introduction of a premature termination codon. The mutation also caused skipping of the upstream exon 17, resulting in the deletion of 42 amino acids (p.Leu472_His513del) [37-39].

Mutation c.385C $>\mathrm{T}$ (chr1:46661719) is a missense mutation results in arginine substitution for tryptophan at position 129 (p.Arg129Trp).
Exome sequencing also revealed heterozygous deletion in the first intron of FKTN gene (IVS1-15delA, c.3515del A). According to the UCSC Genome Browser [40], this deletion is in the middle of the intron and does not affect the splicing sites. This mutation is not described in the literature and databases. There were no mutations in the exons of this gene. Mutations in FKTN are the main cause of the Fukuyama congenital muscular dystrophy. For all of these reasons, we defined this mutation as non-pathogenic.

Diagnostic algorithm for the detection of CMDs contains following steps: assessment of presence or absence of CNS, muscle and vision damage, as well as evaluation of phenotypic features and the plasma level of CK. In the case of CNS involvement, brain MRI is performed. The final step is a molecular study to confirm the diagnosis [41].

Ulrich's disease is the most common form of CMD in Europe but does not cause CNS anomalies [42]. In our 


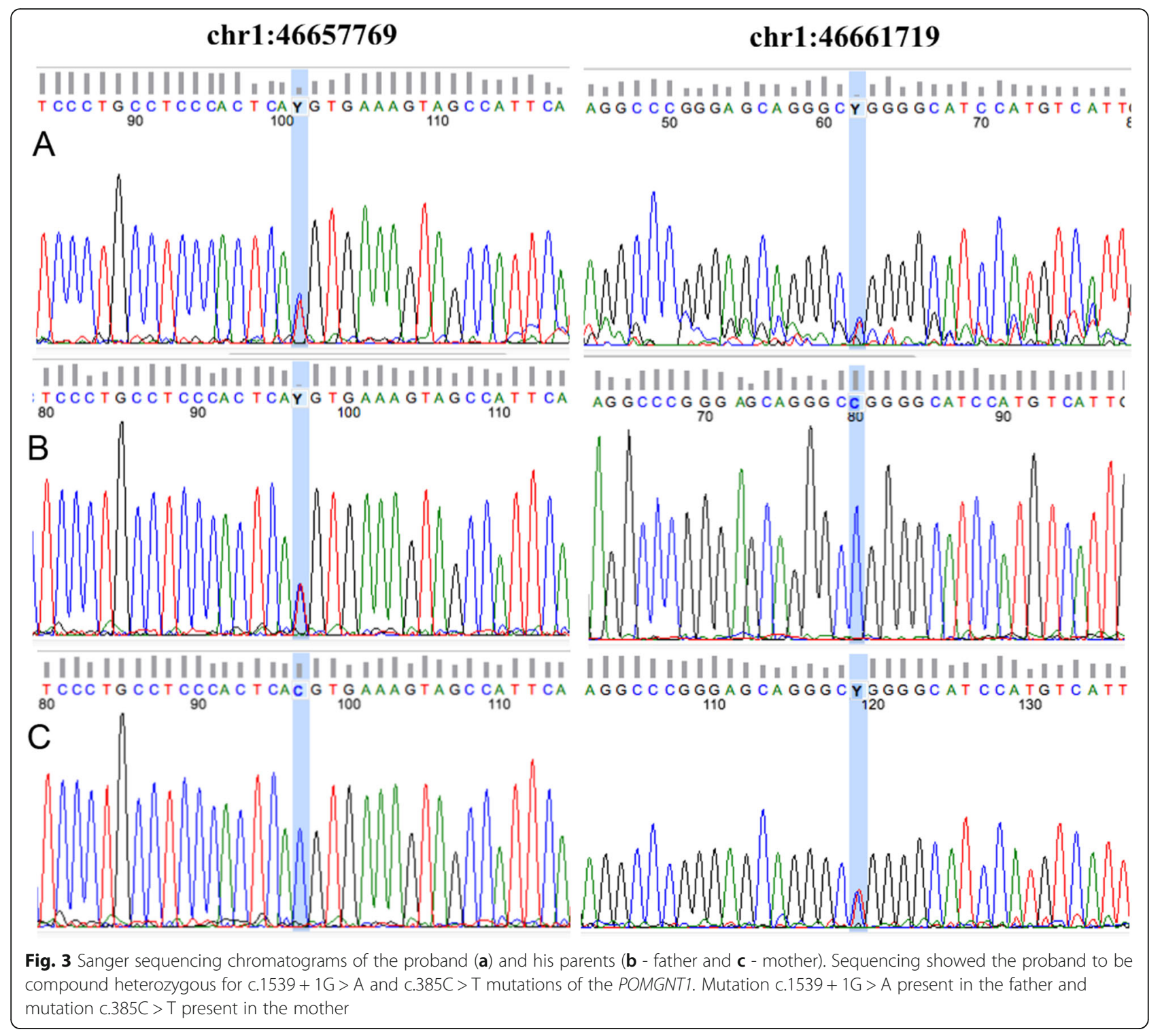

case, this type of CMD was excluded. The revealed by MRI complex of changes can be characteristic for congenital merosin-deficient myodystrophy, type 1A (OMIM 607855). But the specific damage to the organ of vision and absence of contractures of the joints make it possible to exclude this diagnosis. Elevated levels of CK in the patient's blood and signs of CNS involvement suggested the presence of secondary dystroglycanopathy. MRI data confirm this diagnosis. Anomalies corresponding to secondary dystroglycanopathies and detected by MRI are disruption of the formation of brain gyri, combined with a flattening of the cortical pattern, an abnormality of the supratentorial white matter, cerebral cysts, and cerebellar hypoplasia [43].

Dystroglycanopathy is associated with an abnormal $\alpha$-dystroglycan function. $\alpha$-dystroglycan is one of the subunits of dystroglycan and central component responsible for the stability of the myocyte membrane [44]. $\alpha$-dystroglycan is an extracellular membrane glycoprotein that binds to the extracellular matrix component laminin. B-dystroglycan binds to the protein of the cytoskeleton - dystrophin [45]. $\alpha$-dystroglycan is composed of three domains: N-terminal, mucin-like and C-terminal domains. O-mannosylation of the mucin-like domain of $\alpha$-dystroglycan plays an important role in the interaction with laminin. Defects in glycosylation of the $\alpha$-subunit lead to a decrease in binding of the dystroglycan to extracellular matrix proteins, which leads to membrane fragility [46]. The most severe symptoms of dystroglycanopathy are observed with mutations in genes encoding proteins of the O-mannosylation process [47]. $\alpha$-dystroglycan is also 
expressed in neurons and oligodendrocytes and participates in the formation of the brain during fetal development [48]. The role of $\alpha$-dystroglycan in brain development is not fully understood, but it has been shown that it participates in the formation of basal membrane and migration of neurons [45].

Secondary dystroglycanopathies include MEB, WWS syndrome and syndrome FCMD. Genetic analysis was conducted to establish an accurate diagnosis among the variants described.

FCMD syndrome (OMIM 253800) is an autosomal recessive disease characterized by severe muscular dystrophy in combination with CNS lesions (brain polymicrogyria, lissencephaly, agenesis of corpus callosum, ventriculomegaly, cerebellar cysts and hypomyelinization) [49]. Clinical signs of the disease include the development of contractures of large and small joints, heart damage (congenital heart disease, dilated cardiomyopathy). Patients with FCMD syndrome also suffer from epileptic attacks (80\%) and insomnia $(30 \%)$. Also, they have visual problems, such as myopia, retinal dysplasia, atrophy of optic nerve, microphthalmia, cataract. The retardation of mental development in patients with FCMD syndrome is estimated from moderate to severe. Usually, such patients do not live up to 20 years. Mutations in FKTN are the main cause of the Fukuyama congenital muscular dystrophy. FKTN is located on chromosome 9q31 and encodes membrane protein that is believed to have a function similar to glycosyltransferase and may be involved in protein modification after the phosphorylation process [50]. The coding region of FKTN was analyzed by NGS. A nonpathogenic heterozygous deletion in the first intron of this gene was detected (IVS1-15delA, c.3515del A). Based on clinical signs of the patient (absence of contractures and congenital heart diseases) and absence of pathogenic mutations in the FKTN gene, the diagnosis of Fukuyama syndrome was excluded.

MEB disease (or muscular dystrophy-dystroglycanopathy type 3 A, OMIM 253280) is an autosomal recessive disease characterized by congenital muscular dystrophy, visual impairment and defects of brain development (lissencephaly). The average life expectancy of patients with MEB is 10 to 30 years [42]. The most common cause of MEB are mutations in the POMGNT1. All described POMGNT1 mutations lead to complete loss of enzymatic activity of the POMGNT1 protein, responsible for the modification of $\alpha$-dystroglycan after the phosphorylation process. Normally, it catalyzes the addition of the $\mathrm{N}$-acetylglucosamine residue to O-linked mannose [37]. The coding region of POMGNT1 was analyzed by NGS. Two mutations were found, in intron 17 (c.1539+1G > A) and in exon 5 (c.385C > T). Mutation c. $1539+1 \mathrm{G}>\mathrm{A}$ is found in splice site and is registered in the databases as pathogenic (https://www.ncbi.nlm.nih.gov/ clinvar/variation/56582/). Mutation c.385C $>\mathrm{T}$ in the compound heterozygous state is registered with unknown effect (http://databases.lovd.nl/whole_genome/ variants/0000067353\#00014727).

Mutations in the POMGNT1 can lead not only to MEB disease but also to the development of WalkerWarburg syndrome associated with congenital muscular dystrophy, violation of neuronal migration and various visual disorders [51, 52]. However, clinical manifestations (delay in psychomotor development, brain and eye damage) of Walker-Warburg syndrome are more severe. As a result, the average life expectancy of patients with Walker-Warburg syndrome is about three years [53,54]. Based on clinical signs and age of our patient the correct diagnosis is muscular dystrophy-dystroglycanopathy type 3 A (MEB disease).

Thus, based on clinical features (severe delay in psychomotor and speech development, muscle hypotony, congenital myopia, partial atrophy of the optic nerve disc), increased level of CK, ENMG data (primary-muscle lesion), MRI data (polymicrogyria, ventriculomegaly, hypoplasia of the corpus callosum, cysts of the cerebellum) and results of molecular genetic analysis patient was diagnosed: congenital muscular dystrophy-dystroglycanopathy, type 3A (MEB syndrome, with damage to the muscles, eyes and brain).

Identification of disease-causing mutations can provide a proper molecular diagnosis of dystroglycanopathies, which will help to consider more reliable therapeutic approaches and develop information about prognosis.

Currently, there is no specific treatment for dystroglycanopathies. Treatment of such patients focuses on decreasing the severity of symptoms. However, with the limited available therapeutic option for most of the patients, molecular diagnosis might enable geneticists and pediatricians to provide informative genetic counseling, perform prenatal diagnosis, and implement prevention measures for such patients. Therefore, genetic counseling should be recommended to all individuals with dystroglycanopathies and families for their next pregnancies.

In summary, two mutations of the POMGNT1 gene were identified in a compound heterozygous boy with muscular dystrophy-dystroglycanopathy. We described detailed algorithm for correct differential diagnosis of dystroglycanopathies: MEB syndrome, WWS syndrome and FCMD. Our study may help to establish an appropriate genetic counseling and prenatal diagnosis for individuals at the high risk of dystroglycanopathy. 


\section{Abbreviations}

CK: Creatine kinase; CMD: Congenital Muscular Dystrophy; CNS: Central Nervous System; ECG: Electrocardiogram; EEG: Electroencephalography; ENMG: Electroneuromyographic examination; FCMD: Fukuyama congenital muscular dystrophy; MEB: Muscle Eye Brain disease; MRI: Magnetic Resonance Imaging; WWS: Walker-Warburg syndrome

\section{Acknowledgements}

We would like to thank the patients' family for their willingness to take part in this study.

\section{Authors' contributions}

$\mathrm{OB}, \mathrm{AYu}, \mathrm{KYu}, \mathrm{OI}, \mathrm{DO}, \mathrm{Al}, \mathrm{TT}, \mathrm{NV}, \mathrm{El}, \mathrm{PA}, \mathrm{W}$ met the International Committee of Medical Journal Editors (ICMJE) criteria for authorship. OB, DO, Al, El and PA contributed to data collection and the first draft of the manuscript. AYu $\mathrm{KYu}$ and $\mathrm{Ol}$ carried out the mutation analysis. OB, $\mathrm{TT}$ and NV cared for the patient. W was a mentor who contributed equally to this work. All authors read and approved the final manuscript.

\section{Funding}

The work was done within the framework of the State Academies of Sciences Fundamental Scientific Research Program for 2013-2020.

\section{Availability of data and materials}

We did not use new software, databases, or applications/tools in the manuscript, and our raw data has already described in the manuscript and figures.

\section{Ethics approval and consent to participate}

All research was approved by the ethics committee of Genotek Ltd. (08/2018). The patient's parents have provided written informed consent.

\section{Consent for publication}

The patient's parents gave written informed consent to studies and publication of clinical information, images and sequencing data.

\section{Competing interests}

AYu, KYu, OI, DO, El, PA, W are employees of Genotek Ltd. The authors declare that they have no other competing interests.

\section{Publisher's Note}

Springer Nature remains neutral with regard to jurisdictional claims in published maps and institutional affiliations.

\section{Author details}

'Scientific and Practical Centre of Pediatric psychoneurology of Moscow Healthcare Department, Michurinsky prospect, 74, 119602 Moscow, Russia.

${ }^{2}$ Genotek Ltd, Nastavnicheskii pereulok 17/1, 105120 Moscow, Russia. ${ }^{3}$ Pirogov Russian National Research Medical University, Ostrovitianova street 1, 117997 Moscow, Russia. ${ }^{4}$ Institute of Gene Biology, Vavilova street 34/5, 119334 Moscow, Russia. ${ }^{5}$ National Medical Research Centre for Children's Health, Lomonosov prospect 2/1, 119296 Moscow, Russia. ${ }^{6}$ Veltischev Research and Clinical Institute for Pediatrics of the Pirogov Russian National Research Medical University, Taldomskaya str 2, 125412 Moscow, Russia. ${ }^{7}$ Institute of Biomedical Chemistry, Pogodinskaya street 10 building 8, 119121 Moscow, Russia. ${ }^{8}$ Vavilov Institute of General Genetics, Gubkina street 3, 119333 Moscow, Russia.

\section{Received: 26 August 2018 Accepted: 24 March 2019} Published online: 08 April 2019

\section{References}

1. Darin N, Tulinius M. Neuromuscular disorders in childhood: a descriptive epidemiological study from western Sweden. Neuromuscul Disord. 2000;10(1):1-9.

2. Norwood FL, Harling C, Chinnery PF, Eagle M, Bushby K, Straub V. Prevalence of genetic muscle disease in northern England: in-depth analysis of a muscle clinic population. Brain. 2009;132(Pt 11):3175-86. https://doi. org/10.1093/brain/awp236.
3. Mostacciuolo ML, Miorin M, Martinello F, Angelini C, Perini P, Trevisan CP. Genetic epidemiology of congenital muscular dystrophy in a sample from north-East Italy. Hum Genet. 1996:97(3):277-9.

4. Yonekawa T, Nishino I. Ullrich congenital muscular dystrophy: clinicopathological features, natural history and pathomechanism(s). J Neurol Neurosurg Psychiatry. 2015;86(3):280-7. https://doi.org/10.1136/jnnp2013-307052.

5. Taniguchi-lkeda M, Morioka I, lijima K, Toda T. Mechanistic aspects of the formation of a-dystroglycan and therapeutic research for the treatment of a-dystroglycanopathy: a review. Mol Asp Med. 2016;51:115-24. https://doi. org/10.1016/j.mam.2016.07.003.

6. Durbeej M. Laminin-a2 chain-deficient congenital muscular dystrophy: pathophysiology and development of treatment. Curr Top Membr. 2015;76:31-60. https://doi.org/10.1016/bs.ctm.2015.05.002.

7. Falsaperla R, Praticò AD, Ruggieri M, Parano E, Rizzo R, Corsello G, et al. Congenital muscular dystrophy: from muscle to brain. Ital J Pediatr. 2016:42(1):78. https://doi.org/10.1186/s13052-016-0289-9.

8. Shieh PB. Muscular dystrophies and other genetic myopathies. Neurol Clin 2013;31(4):1009-29. https://doi.org/10.1016/j.ncl.2013.04.004

9. Graziano A, Bianco F, D'Amico A, Moroni I, Messina S, Bruno C, et al. Prevalence of congenital muscular dystrophy in Italy: a population study. Neurology. 2015; 84(9):904-11. https:/doi.org/10.1212/WNL.0000000000001303.

10. Barresi R, Campbell KP. Dystroglycan: from biosynthesis to pathogenesis of human disease. J Cell Sci. 2006;119(Pt 2):199-207.

11. Zhang QZ. Dystroglycan induced muscular dystrophies - a review. Eur Rev Med Pharmacol Sci. 2016;20(17):3683-7.

12. Vajsar J, Schachter H. Walker-Warburg syndrome. Orphanet J Rare Dis. 2006; $1 \cdot 29$

13. Sato T, Adachi M, Nakamura K, Zushi M, Goto K, Murakami T, et al. The gross motor function measure is valid for Fukuyama congenital muscular dystrophy. Neuromuscul Disord. 2017;27(1):45-9. https://doi.org/10.1016/j. nmd.2016.09.014.

14. Savarese M, Di Fruscio G, Torella A, Fiorillo C, Magri F, Fanin M, et al. The genetic basis of undiagnosed muscular dystrophies and myopathies: results from 504 patients. Neurology. 2016;87(1):71-6. https://doi.org/10.1212/WNL. 0000000000002800

15. Martin M. Cutadapt removes adapter sequences from high-throughput sequencing reads. EMBnet.journal. 2011:17:10-2.

16. Li H, Durbin R. Fast and accurate short read alignment with burrowswheeler transform. Bioinformatics. 2009;25(14):1754-60.

17. Li H, Handsaker B, Wysoker A, Fennell T, Ruan J, Homer N, et al. The sequence alignment/map format and SAMtools. Bioinformatics. 2009:25(16):2078-9.

18. FastQC: a quality control tool for high throughput sequence data. https:// www.bioinformatics.babraham.ac.uk/projects/fastac/.

19. McKenna A, Hanna M, Banks E, Sivachenko A, Cibulskis K, Kernytsky A et al. The genome analysis toolkit: a MapReduce framework for analyzing next-generation DNA sequencing data. Genome Res. 2010:20(9):1297-303.

20. DePristo MA, Banks E, Poplin R, Garimella KV, Maguire JR, Hartl C, et al. A framework for variation discovery and genotyping using next-generation DNA sequencing data. Nat Genet. 2011;43(5):491-8.

21. Van der Auwera GA, Carneiro MO, Hartl C, Poplin R, del Angel G, LevyMoonshine A, et al. From FastQ data to high confidence variant calls: the genome analysis toolkit best practices pipeline. Curr Protoc Bioinformatics. 2013;11(1110):11.10.1-11.10.33.

22. Cingolani $P$, Platts $A$, Wang $L L$, Coon $M$, Nguyen $T$, Wang $L$, et al. A program for annotating and predicting the effects of single nucleotide polymorphisms, SnpEff: SNPs in the genome of Drosophila melanogaster strain w1118; iso-2; iso-3. Fly (Austin). 2012:6(2):80-92.

23. Liu X, Wu C, Li C, Boerwinkle E. dbNSFP v3.0: a one-stop database of functional predictions and annotations for human non-synonymous and splice site SNVs. Hum Mutat. 2016;37(3):235-41.

24. ClinVar. http://www.ncbi.nlm.nih.gov/clinvar/. Accessed 23 Aug. 2018.

25. Landrum MJ, Lee JM, Benson M, Brown G, Chao C, Chitipiralla S, et al ClinVar: public archive of interpretations of clinically relevant variants. Nucleic Acids Res. 2016;44(Database issue):D862-8.

26. OMIM database (Online Mendelian Inheritance in Man). https://omim.org/. Accessed 23 Aug 2018

27. The Human Gene Mutation Database. http://www.hgmd.cf.ac.uk/ac/gene. php?gene. Accessed 23 Aug. 2018. 
28. Ng PC, Henikoff S. SIFT: predicting amino acid changes that affect protein function. Nucleic Acids Res. 2003;31(13):3812-4.

29. PolyPhen-2 (Polymorphism Phenotyping v2). http://genetics.bwh.harvard. edu/pph2/. Accessed 23 Aug. 2018.

30. Adzhubei I, Jordan DM, Sunyaev SR. Predicting functional effect of human missense mutations using PolyPhen-2. Curr Protoc Hum Genet. 2013; Chapter 7:Unit7.20. doi: https://doi.org/10.1002/0471142905.hg0720s76.

31. 1000Genomes project. http://browser.1000genomes.org/index.html. Accessed 23 Aug 2018.

32. 1000 Genomes Project Consortium, Auton A, Brooks LD, Durbin RM, Garrison EP, Kang HM, et al. A global reference for human genetic variation. Nature. 2015;526(7571):68-74.

33. ExAC (Exome Aggregation Consortium). http://exac.broadinstitute.org/. Accessed 23 Aug. 2018.

34. Lek M, Karczewski KJ, Minikel EV, Samocha KE, Banks E, Fennell T, et al. Analysis of protein-coding genetic variation in 60,706 humans. Nature. 2016; 536(7616):285-91.

35. Richards S, Aziz N, Bale S, Bick D, Das S, Gastier-Foster J, et al. Standards and guidelines for the interpretation of sequence variants: a joint consensus recommendation of the American College of Medical Genetics and Genomics and the Association for Molecular Pathology. Genet Med. 2015:17(5):405-23.

36. Talevich E, Shain AH, Botton T, Bastian BC. CNVkit: genome-wide copy number detection and visualization from targeted sequencing. PLoS Comput Biol. 2014;12(4):e1004873.

37. Yoshida A, Kobayashi K, Manya H, Taniguchi K, Kano H, Mizuno M, et al. Muscular dystrophy and neuronal migration disorder caused by mutations in a glycosyltransferase, POMGnT1. Dev Cell. 2001;1(5):717-24.

38. Taniguchi K, Kobayashi K, Saito K, Yamanouchi H, Ohnuma A, Hayashi YK, et al. Worldwide distribution and broader clinical spectrum of muscle-eyebrain disease. Hum Mol Genet. 2003;12(5):527-34.

39. Diesen C, Saarinen A, Pihko H, Rosenlew C, Cormand B, Dobyns WB, et al. POMGnT1 mutation and phenotypic spectrum in muscle-eye-brain disease. J Med Genet. 2004;41(10):e115.

40. UCSC Genome Browser https://genome.ucsc.edu/ Accessed 23 Aug. 2018.

41. Lisi MT, Cohn RD. Congenital muscular dystrophies: new aspects of an expanding group of disorders. Biochim Biophys Acta. 2007;1772(2):159-72.

42. Gilbreath HR, Castro D, lannaccone ST. Congenital myopathies and muscular dystrophies. Neurol Clin. 2014;32(3):689-703.

43. Vuillaumier-Barrot S, Bouchet-Séraphin C, Chelbi M, Devisme L, Quentin S, et al. Identification of mutations in TMEM5 and ISPD as a cause of severe cobblestone lissencephaly. Am J Hum Genet. 2012;91(6):1135-43.

44. Chandrasekharan K, Martin PT. Genetic defects in muscular dystrophy Methods Enzymol. 2010;479:291-322.

45. Endo T. Glycobiology of a-dystroglycan and muscular dystrophy. J Biochem. 2015;157(1):1-12.

46. Gomez Toledo A, Raducu M, Cruces J, Nilsson J, Halim A, Larson G, et al. Omannose and O-N-acetyl galactosamine glycosylation of mammalian adystroglycan is conserved in a region-specific manner. Glycobiology. 2012:22(11):1413-23.

47. Martin PT. Congenital muscular dystrophies involving the O-mannose pathway. Curr Mol Med. 2007;7(4):417-25

48. Waite A, Brown SC, Blake DJ. The dystrophin-glycoprotein complex in brain development and disease. Trends Neurosci. 2012;35(8):487-96.

49. Saito K. Fukuyama congenital muscular dystrophy. GeneReviews ${ }^{\oplus}$ [internet]. Seattle (WA): University of Washington, Seattle; 1993-2017.

50. Kobayashi K, Nakahori Y, Miyake M, Matsumura K, Kondo-lida E, Nomura Y, et. al. An ancient retrotransposal insertion causes Fukuyama-type congenital muscular dystrophy. Nature. 1998;394(6691):388-392.

51. Bedri HA, Mustafa BM, Jadallah YM. Walker-Warburg syndrome: a case with multiple uncommon features. Sudan J Paediatr. 2011;11(2):59-63.

52. Godfrey C, Clement E, Mein R, Brockington M, Smith J. et. al. Refining genotype phenotype correlations in muscular dystrophies with defective glycosylation of dystroglycan. Brain. 2007;130(Pt 10):2725-2735.

53. Mercuri E, Messina S, Bruno C, Mora M, Pegoraro E, Comi GP, et al. Congenital muscular dystrophies with defective glycosylation of dystroglycan: a populationstudy. Neurology. 2009;72(21):1802-9.

54. Dobyns WB, Pagon RA, Armstrong D, Curry CJ, Greenberg F, Grix A, et al. Diagnostic criteria for Walker-Warburg syndrome. Am J Med Genet. 1989;32(2):195-210.

\section{Ready to submit your research? Choose BMC and benefit from:}

- fast, convenient online submission

- thorough peer review by experienced researchers in your field

- rapid publication on acceptance

- support for research data, including large and complex data types

- gold Open Access which fosters wider collaboration and increased citations

- maximum visibility for your research: over $100 \mathrm{M}$ website views per year

At BMC, research is always in progress.

Learn more biomedcentral.com/submissions 